\title{
Land of My Fathers? Economic Development, Ethnic Division and Ethnic National Identity in 32 Countries
}

\author{
by Robert Ford, James Tilley and Anthony Heath \\ University of Manchester; University of Oxford; University of Oxford
}

\author{
Sociological Research Online, 16 (4) 8 \\ $<$ ttp://www. socresonline.org.uk/16/4/8. html> \\ $10.5153 /$ sro. 2508
}

Received: 7 Jan 2011 Accepted: 14 Nov 2011 Published: 30 Nov 2011

\begin{abstract}
We investigate the reasons why some people, and some countries, place greater or lesser emphasis on the idea that membership of a nation is tied to ancestry. We test the influence of two key factors economic development and ethnic division. Economic development is strongly associated with support for the ancestry criterion of national membership. Those who are more economically secure, who grew up in wealthier nations, or live in a wealthier nation currently, are less likely to emphasise ancestry as an important factor in national identity. Those who have grown up since mass immigration to a country begun are also less likely to emphasise ancestry. However, we find no evidence that historical conditions are correlated with current national identity beliefs.
\end{abstract}

\section{Keywords: National Identity, Comparative, Survey, Generational Change}

\section{Introduction}

1.1 Since the pioneering work of Meinecke (1907) and Kohn (1944), conceptions of national identity have been divided into two ideal types: ethnic identity, where membership of the nation is broadly believed to be based on a shared cultural heritage, and civic identity, where membership is instead primarily a matter of loyalty to the political institutions of the nation. While empirical analysis has confirmed that the distribution of beliefs about national identity does not conform to the clear distinctions drawn by early theorists, individuals in nearly all societies do differentiate between "civic" ideas of national group membership, which emphasise such factors as loyalty to the state and respect for its institutions, and "ethnic" ideas such as birth and ancestry (Smith and Jones, 2001a; Hjerm, 2003; Reeskens and Hooghe, 2010). Some individuals, and some societies, clearly do place more emphasis on ethnic ideas of national membership than others. Moreover, a growing body of research suggests these differences have important implications, with ethnic nationalism at individual and national level predicting hostility towards immigrants and minority groups (Hjerm, 1998; Heath and Tilley, 2005).

1.2 The central question we therefore seek to investigate is: why do some countries, and some individuals, place greater emphasis on ethnic nationalism than others? Mindful of the differences between nations in the interpretation of nationalist ideas (Reeskens and Hooghe, 2010) we focus on the item which comparative research reveals is most strongly associated with ethnic nationalism in all countries: the belief that ancestry is an important measure of national group membership. We test hypotheses operating at three different levels, and of two different types, one concerning economic development and one ethnic division. At the individual level, we test hypotheses concerning the impact of education, social class and immigrant status. The common argument linking all three is that factors which make an individual more economically secure and accepting of diversity will be associated with reduced emphasis on an ethnic national identity. At the cohort level, we test the idea that the economic and social conditions prevalent during the "socialisation period" of early adulthood have a lasting impact on national identity beliefs, with those coming of age in poorer or more ethnically homogenous conditions retaining a greater attachment to ethnic forms of national identity. At the national level, we test four key comparative hypotheses: we expect ethnic identity to be more prevalent in countries that are relatively poor; in more ethnically homogenous societies, even after controlling for the different beliefs of ethnic minorities themselves; in countries that were rich when they first became independent nations; and in countries that emerged by a process of ethnic secession, particularly if that process was violent.

\section{Civic and ethnic nationalism}

2.1 Two ideal types of national identity are generally conceived in the literature. On the one hand, a territorial or civic identity, thought to have developed first in the unified and industrialising nation states of the Atlantic coast, in particular Britain and France, during the 19th century (Kohn 1944; Hobsbawm 1990; although see Colley 1996 for a different perspective). Civic identity focuses upon the political aspects of national identity, where national identity is thought of as a matter of living within a nation's borders, possessing its citizenship and obeying its laws. All those who live within a nation are thought of as equally its citizens, regardless of their culture or background; identity is thus a choice, it can be acquired by 
2.2 The second is ethnic, cultural or particularistic nationalism, ${ }^{[1]}$ which argues that political allegiance and legal citizenship are not sufficient for membership of the national group. To be a "true" member of the nation an individual must also have deep roots in the nation's society and culture. As Walker Connor has argued, a common belief in shared ancestry is central to this idea of national identity:

"One answer, then, to the often asked question 'What is a nation?' is that it is a group of people who feel they are ancestrally related. It is the largest group that can command a person's loyalty because of felt kinship ties; it is, from this perspective, the fully extended family" (Connor 1994:202)

2.3 Ethnic nationalism has generally been held in low esteem by liberal theorists. It has been variously described as "excessive and militant" (Kohn 1944, p24); an "illiberal and belligerent doctrine" (Miller 1995, p8); and "exclusivist, xenophobic, expansionist and oppressive" (Guibernau 1996, pp51-7). The main reason so many theorists have taken a negative view of ethnic nationalism has been its perceived association with intolerance in various forms. Ethnic nationalism has been associated with militant violence within and between states (Brubaker and Laitin 1998) and with extreme right political movements which mobilise hostility to both historic minorities such as Hungarians in Romania and Slovakia and to the new migrant minorities who have settled in most Western societies in recent decades (Mudde 2007). These extreme right groups make frequent use of ethnic nationalist themes to argue that minority groups are an alien threat to the national culture, and that the interests of the (ethnic) nationals should be put before those of alien minorities.

2.4 The degree to which a nation, or significant portions of a nation's citizens, emphasises ancestry and cultural heritage as a necessary condition for membership of the national group is thus likely to have important social consequences, in particular relating to the treatment of migrants and minorities. As most ethnic nationals would regard such migrants, or even their children, as resident aliens rather than true nationals, they may feel disinclined to grant them political rights or social welfare benefits, which they may prefer to reserve for those they regard as their kinsmen. They may also become alarmed if the immigrant descended population grows rapidly, regarding it as a threat to the ethnic national culture. Immigrant minorities may therefore face greater difficulty gaining acceptance from others, greater discrimination in employment markets and greater hostility in everyday life (Hjerm 1998; Ivarsflaten 2005).

2.5 Several empirical studies have attempted to operationalise these concepts of civic and ethnic nationalism using survey data and test their prevalence among mass publics. Jones and Smith $(2001 a, b)$ demonstrated that responses to a battery of eight questions about national identity asked by the International Social Survey Programme tend to cluster into two broadly "civic" and "ethnic" factors in most of the nations which had fielded the module. Kunovich (2009) identifies a similar pattern, but notes that the main distinction appears to be between "civic" nationalists who only emphasise civic criteria, and "pluralist" nationalists who additionally emphasise ethnic criteria. Shulman (2002) has shown similar evidence of overlap between civic and ethnic ideas, with considerable support for ethnic ideas exists in the supposedly more civic Western European nations, and widespread support for civic nationalist ideas in the supposedly more ethnic nations of Eastern Europe (see also Bjorklund 2006).

2.6 Reeskens and Hooghe (2010) have argued that these recent analyses have relied too heavily on factors derived from the aggregate cross-national data, which may not be robust to individual nations. They note that while the civic/ethnic divide has clear support in the overall data, there is considerable variation in how citizens of different countries think about these concepts. For example, respondents in Israel and Poland place a greater emphasis on religion as a measure of "ethnic" identity, while Irish respondents place less emphasis on language. The authors conclude that comparative analysis based upon individual and national scores on each of the two dimensions of nationality is not robustly grounded in the data and is likely to be misleading. There are simply too many deep-rooted differences in the way different nations combine the various components of the "civic" and "ethnic" identity concepts. They suggest researchers should focus instead on those items which are most invariant across nations. In particular, they note a strong consensus across the nations in their sample that ancestry and descent are an essential part of "ethnic" identity and that a commitment to upholding the nation's laws is an essential part of "civic" identity.

Table 1. Support for respect for institutions versus national ancestry as important components of national identity

\begin{tabular}{|c|c|c|c|c|c|c|}
\hline & & \multicolumn{5}{|c|}{ National ancestry } \\
\hline & & $\begin{array}{l}\text { Notat all } \\
\text { important }\end{array}$ & $\begin{array}{l}\text { Notvery } \\
\text { important }\end{array}$ & $\begin{array}{l}\text { Fairly } \\
\text { important }\end{array}$ & $\begin{array}{l}\text { Very } \\
\text { important }\end{array}$ & $\operatorname{All}(\mathrm{N})$ \\
\hline \multirow{6}{*}{$\begin{array}{l}\text { Respect laws/ } \\
\text { institutions }\end{array}$} & Not at all important & $1 \%$ & $1 \%$ & $1 \%$ & $1 \%$ & $3 \%(1,417)$ \\
\hline & Not very important & $1 \%$ & $3 \%$ & $3 \%$ & $2 \%$ & $9 \%(3,703)$ \\
\hline & Fairly important & $5 \%$ & $9 \%$ & $16 \%$ & $8 \%$ & $38 \%(15,614)$ \\
\hline & Very important & $8 \%$ & $11 \%$ & $9 \%$ & $22 \%$ & $50 \%(20,968)$ \\
\hline & All & $15 \%$ & $23 \%$ & $29 \%$ & $33 \%$ & $100 \%(41,702)$ \\
\hline & $(\mathrm{N})$ & & $(9,816)$ & $(11,961)$ & $(13,848)$ & \\
\hline
\end{tabular}

2.7 In Table 1, we show a simple cross-tabulation of these two core items. It is clear from this table that contrasting pure ethnic nationalism with pure civic nationalism is not really feasible, for the simple reason that almost all of our cross national sample saw the core civic item as important pre-requisite for membership of the national group: 88 per cent said that respect that for the laws and institutions of their country was fairly or very important for being of that nationality. ${ }^{[2]}$ What Table 1 demonstrates is that it is more sensible to talk of ethnic nationalism in addition to civic nationalism, rather than ethnic nationalism 
as opposed to civic nationalism. The vast majority of respondents in our sample are civic nationalists, at least in terms of regarding acceptance of their nation's laws and institutions as essential to becoming a member of the nation, but some are additionally ethnic nationalists. These individuals are in effect arguing that the civic ideal is not sufficient - those who accept a nation's laws still do not belong to that nation if they do not share in the nation's heritage. This has implications for how we might want to model nationalist beliefs. As there is relatively little variation in the emphasis placed on the core "civic" item of obedience to the laws and institutions of the nation, we focus instead on the core "ethnic" nationalist statement, about ancestry, and see how this varies by individuals, and, when aggregated, by countries. This avoids the ambiguities and measurement difficulties that Reeskens and Hooghe identify while retaining the empirically grounded focus on the distinction between "civic" nationalists and "civic and ethnic" nationalists.

\section{Theory and hypotheses}

\section{Economic development}

3.1 Many theorists have pointed to the processes of economic and social development associated with the industrial revolution as a key to understanding the forging of national identities. Different theorists have emphasised different aspects of this process: the development of transport links connecting all areas of a national territory and the rise of "print capitalism" encouraging communication between them in a standardised written language (Anderson 1983); the movement of masses from farm to factory pressed together groups with no previous contact, helping to create a new, more homogenous urban dominated cultures which are then used to integrate citizens in more fluid, dynamic modern societies (Gellner 1983); and the growing power of a coercive centralised state through the expansion of bureaucratic, military and surveillance institutions, providing intensive, uniform administration of state rule across a territory (Tilly 1975; Giddens 1987). All these accounts emphasise that the growth of new economic and social structures associated with the rise of capitalist industrialised economies generated new cultural and ideological tools for legitimating the state, which generally take the form of a politically focussed civic nationalism.

3.2 Related to this is Kohn's argument, revived by Anthony Smith (Smith 1995 p71-84), that the size of the middle class at the time of nationalist movement emergence is crucial to the character of the movement. Nationalist movements mobilising in more economically advanced countries with a large educated bourgeoisie tend to be like that bourgeoisie - moderate, civic-minded and politically focussed, whereas nationalisms emerging in areas with no established bourgeoisie tend to be fostered by a small intelligentsia and targeted at a large, uneducated peasantry. As a result, they are "authoritarian, mystical and 'organic"' (Smith 1995 p75). Hobsbawm makes a similar point, contrasting the nationalist movements in 19th century industrialising nations, which were "typically unificatory as well as emancipatory" with more recent nationalisms emerging in economically less developed regions, which he describes as "reactions of weakness and fear, attempts to erect barricades to keep at bay the forces of the modern world" (Hobsbawm 1990 p164). Gellner (1983) similarly points to the important effects of uneven economic development on nationalism in culturally diverse empires - rapid economic progress benefits the ruling urban cultures concentrated in the industrialising cities of the empire, while leaving behind the agrarian cultures in its rural fringes. While the former group will favour inclusive civic forms of nationalism to hold together the empire they dominate, the latter group will turn to ethnic nationalism as an outlet for expressing and mobilising their grievances and seeking redress through recognition, or secession.

3.3 Jonathan Hearn (2006) has criticised these accounts for assuming that nationalism is the product of a particular historical stage in economic and social development, and neglecting the possibility that nationalist beliefs may continue to respond to contemporary social and economic change. Hearn points out how the forces of economic and social integration which freed individuals from traditional social roles and, on the modernisation account, helped generate nationalist movements, have continued to alter the governance capacity of nation-states and the level of integration across borders through to the present day (Hearn 2006 p 104-6). We may therefore expect continued change in the nature of nationalism in response to these forces (Mann 1996). In particular, we expect that as countries, and individuals within those countries, become more prosperous and economically integrated, their attachment to ethnic nationalist ideas which tie national membership to a particular culture and heritage will lose their appeal.

3.4 The common point in these arguments is that the processes of economic and social integration associated with modernisation - industrialisation, urbanisation, the development of transport and communications infrastructure - play a crucial role in shaping nationalist ideas. We aim to test this argument in four different contexts. At the individual level, we expect that factors which are likely to be associated with greater access to modern transport and communications infrastructure and exposure to other societies will be associated with a lower support for ancestry as a measure of national identity. The particular factors we focus on are education and social class. Highly educated individuals are more likely to be exposed to the cultures and traditions of other countries, which should reduce their attachment to an ethnic sense of national identity. Education may also be important for a second reason. A large literature on cognitive sophistication (McCrone and Surridge 1998; Day and Thompson 2004, ch.9 and conclusion) has argued that better-educated individuals tend to become more cosmopolitan, identifying with larger and more varied groups, especially groups outside the nation. ${ }^{[3]}$ Those with professional or middle class jobs are also more likely to be exposed to a wider range of cultures and to experience benefits from international economic integration.

3.5 The national context in which individuals are located is likely to also exert an influence. The well documented processes of growing global economic integration over the past three decades (Day and Thompson 2004, ch. 9; Holton 1998; Smith 1995) may change the way nations view themselves. Rising international trade, and growing economic and cultural integration among more developed countries, should reduce the importance of ethno-national identities (Dogan 1994; Hobsbawm 1990, ch. 6), creating "a world which can no longer be contained within the limits of 'nations'...either politically, or economically, or culturally, or even linguistically." (Hobsbawm 1990, p182). Those in more economically developed societies, who have experienced far greater social and economic integration with other nations through modern transport, trade and communications networks, should therefore be less attached to a sense of nationhood which emphasises ancestral roots.

3.6 The present day economic context may not be the only relevant one to consider. Since the pioneering work of Karl Mannheim (Mannheim, 1952) on generational differences, sociologists have argued persuasively that many core social and political values are mainly shaped during a "socialisation period" during adolescence and early adulthood, and remain relatively fixed thereafter (Inglehart 1997; Tilley 2001, 
2005; Ford 2008). It is certainly plausible to argue individuals' beliefs about national identity could be similarly shaped by socialisation processes, and indeed large generational differences have been identified in British national identity beliefs (Tilley, Exley and Heath, 2004). We therefore hypothesise that the economic conditions prevalent in a respondent's youth will also have a lasting impact on their national identity beliefs, resulting in generational differences in attitudes which reflect the pattern of economic development within each society.

3.7 While contemporary economic development may be important, one clear implication of the arguments made by modernisation theorists is that economic development during the early period when national movements first mobilised can exercise a lasting impact on the form of nationalism which operates in a particular state. The effects of conditions when a nation was first founded, or when nationalist movements first mobilised in an existing state, may have a lasting influence on institutions, culture and elite behaviour, as well as the symbols and mythology of the national narrative. Once institutionalized in this way, these particular foundational conditions may continue to shape how a nation sees itself right through to the present day. Our expectation is thus that countries which were more economically developed at the point either of independence or when nationalism first became a serious force in an existing state will place less emphasis on the ethnic criterion of ancestry than countries that were relatively less modernised at this point.

\section{Ethnic division}

3.8 The second overarching factor we consider in depth is ethnic division. The core idea is that the presence of divisions based on ethnic or cultural differences between the majority national group and minorities living in the same nation-state will have an important effect on national identity beliefs. In many of the contemporary societies of our sample, the most salient source of such ethnic division in recent decades has been mass migration. Many previously ethnically homogenous nations, particularly in Western Europe, now find themselves with large and diverse ethnic minority populations as a result of large inflows of migrants from across the world. Nations whose traditional identities were formed in an era of relative ethnic and cultural homogeneity now face the reality of rapidly diversifying populations.

3.9 Ethnic diversity may influence conceptions of citizenship at the individual level, through differences in the attitudes of immigrant minorities themselves, and at the national and cohort level, through their impact on the national identity attachments of majority group members. New immigrant minorities are unlikely to find much appeal in ethnically derived conceptions of citizenship that will exclude them from the national group, and will therefore tend to more civic conceptions of the national community which will enable them to join as full members. At the national level, governments seeking to integrate such minorities will emphasise more inclusive, civic definitions of national group membership. As immigrant minorities become more established, a growing section of the majority group population will also have regular contact with immigrant minorities, which should lead to greater acceptance of these groups as part of the national group (McLaren 2003). ${ }^{[4]}$

3.10 The effects of contextual diversity during socialisation may also have a lasting impact on attitudes to immigrant minorities. Those who grow up during the first wave of mass migration to a country will be the first to experience migration generated diversity as a normal part of the society they live in. Their children will in turn be the first to grow up with the immigrant "second generation" - people born and raised in their country, but in households steeped in the different culture and traditions of the migrant homeland. We hypothesise that those growing up in a more diverse context will be more accepting of diversity (Ford 2008) and will therefore express less support for the ancestry measure of national identity, which would exclude migrant minorities from national group membership.

3.11 Ethnic division during a nation's early formative period may also exercise a lasting impact, although the dynamic here is somewhat different. Instead of immigration generating increased diversity in states whose borders are largely fixed, ethnic division in the early period of nationalist movements has principally concerned relationships with existing state institutions. Kohn (1944) emphasised the key distinction between territories where the institutions and the borders of the state were largely in place before the emergence of nationalist ideas, and where nationalism subsequently served as a legitimating device, and territories where emergent nationalist movements mobilized in protest against the existing state pattern and sought to change it. Breuilly (1993) similarly points out the central distinction between nationalist movements seeking to separate from another state, those seeking to unify disparate areas into a larger state, and those seeking to reform the existing state they find themselves within. Brubaker (1996) also highlights the importance of the configuration of state and ethnic group arrangements, contrasting "nationalising nationalisms" where a numerically dominant ethnocultural group looks to consolidate its hold on state power; "homeland nationalisms" where a dominant ethnocultural group in one state seeks to protect group members who are marginalized minorities in other states and "minority nationalisms" in which marginalised minority groups seek statehood or other forms of recognition to protect their interests.

3.12 All of these accounts agree on a central premise: nationalist movements that have sought to mobilise the people within a territory against its existing rulers are very different to those movements that emerged to consolidate and support the existing power structure. Secessionist nationalist movements will tend to emphasize the strength of cultural and ethnic differences between rulers and ruled to support their arguments for independence; whereas centralising nationalist movements will conversely seek to emphasise shared values and attachments between diverse citizens forged through their loyalty to a common central state, particularly if, as in cases like Britain, Spain, or 19th century France (Weber 1976) the central state encompasses territories with distinct identities and traditions. Such differences in the political context in which a nation emerged may have a lasting impact as early nationalist ideologies become reinforced and institutionalised after independence. We hypothesise that both foundational circumstances and the presence of violence could be significant. Secessionist nationalist movements based on pressuring for a change in state boundaries will tend to produce a more strongly ethnic national identity. If the movement is violent, we expect the consequent pattern of nationalism will be more ethnic still, as conflict will polarize the attitudes of the seceding group and harden the boundaries it draws between itself and the ruling ethnic group.

\section{Analysis}


4.1 The data we use comes from the 'National Identity II' module of the International Social Survey Programme (ISSP) surveys, which were conducted in 2003. A total of 32 countries conducted the module as part of national sample surveys. ${ }^{[5]}$ These 32 countries represent a reasonable spread of mostly advanced industrial societies. As part of the 2003 ISSP a specific battery of questions was asked to try and tap into ideas of civic and ethnic national identity. Respondents were asked the following questions:

Some people say that the following things are important for being truly [your nationality]. Others say that they are not important. How important do you think each of the following is [Very important/ Fairly important/ Not very important/ Not important at all/ Can't choose]:

a) To have been born in [your nation].

b) To have [your national] citizenship.

c) To have lived in [your nation].

d) To be able to speak [your national language].

e) To be a [your national religion].

f) To respect [your nation]'s political institutions and laws.

g) To feel [your nationality].

h) To have [your national] ancestry.

4.2 We focus on the ancestry question from this battery, which is strongly associated in all national samples with an "ethnic" conception of national identity, and also shows considerable variation between different nations. As Table 2 suggests, there is a great deal of variation in this core measure, both within countries and between countries. Table 2 ranks the countries by their mean scores on the ancestry item, where 'very important' has been coded 4 , 'fairly important' 3 , 'not very important' 2 and 'not at all important' 1 . There are both large variations within countries as to the type of national identity that individuals hold (with an overall standard deviation of over 1 on our four point ancestry question), and considerable variation across countries as to the mean score. Indeed, the cross-national variation displayed in Table 2 is not dissimilar to our expectations about the effects of modernisation and ethnic division. The poorer countries in our sample - such as Venezuela, the Philippines and Poland - tend to cluster at the top of the table while richer countries such as Switzerland, Canada and Sweden cluster at the bottom. The countries near the top of the table tend also to be countries which have not experienced large scale migration (for example Japan), while those at the bottom include countries such as Canada and Switzerland which have experienced very large migration inflows.

Table 2. Countries ranked by their mean score for the ancestry question

\begin{tabular}{lccc}
\hline Country & Mean ancestry score & Standard deviation & $N$ (unweighted) \\
\hline Philippines & 3.67 & 0.58 & 1,197 \\
Venezuela & 3.45 & 0.82 & 1,180 \\
Chile & 3.31 & 0.89 & 1,493 \\
Poland & 3.30 & 0.78 & 1,256 \\
Hungary & 3.18 & 0.89 & 998 \\
South Africa & 3.18 & 0.90 & 2,404 \\
Ireland & 3.16 & 0.92 & 1,051 \\
Portugal & 3.16 & 0.79 & 1,506 \\
Russia & 3.12 & 0.97 & 2,318 \\
Japan & 3.06 & 0.97 & 1,065 \\
South Korea & 3.06 & 0.85 & 1,309 \\
Uruguay & 3.06 & 1.00 & 1,099 \\
Spain & 2.99 & 0.79 & 1,189 \\
Czech & 2.92 & 0.89 & 1,193 \\
Denmark & 2.81 & 1.00 & 1,290 \\
New Zealand & 2.80 & 1.08 & 996 \\
Austria & 2.75 & 1.13 & 964 \\
United States & 2.71 & 1.06 & 1,187 \\
Norway & 2.68 & 1.07 & 1,417 \\
Finland & 2.64 & 1.03 & 1,297 \\
Slovakia & 2.63 & 1.03 & 1,115 \\
Slovenia & 2.60 & 1.04 & 1,077 \\
& & &
\end{tabular}




\begin{tabular}{lccc} 
Taiwan & 2.59 & 0.99 & 1,951 \\
Israel & 2.57 & 1.10 & 1,206 \\
Britain & 2.55 & 1.11 & 819 \\
Germany & 2.54 & 1.03 & 1,241 \\
France & 2.51 & 1.12 & 1,508 \\
Canada & 2.41 & 1.01 & 1,190 \\
Australia & 2.27 & 1.09 & 2,070 \\
Switzerland & 2.26 & 0.98 & 971 \\
Sweden & 2.04 & 1.06 & 1,163 \\
Netherlands & 1.90 & 0.97 & 1,764 \\
& & & \\
Total (all countries & & & \\
weighted equally) & 2.81 & & \\
\hline
\end{tabular}

\section{Explaining differences in national identity}

4.3 The central task of this paper is to explain why some people, and therefore some countries, choose to use the ethnic criterion of ancestry as an important part of their national identity. As discussed, in terms of the important causes of difference we focus here on foundational context, in terms of historic economic development and ethnic division, and current context in terms of contemporary economic development and ethnic diversity caused by immigration. The effect of both is likely to be a dual process. On the one hand factors common to individuals across countries are likely to influence the perceived importance of ancestry. On the other hand it also seems likely that shared context within a particular country is likely to have large effects on national identity, although the relevant context may be the conditions prevalent when cohorts come of age as much as present conditions. In order to successfully model national identity using both individual-level variables and country-level variables, we specify a hierarchical model by introducing random intercept coefficients, which explicitly takes account of the two level (country and individual) nature of the data. ${ }^{[6]}$ Hierarchical models correct for the dependence of observations within countries (intra-class correlation) and make adjustments to both within and between parameter estimates for the clustered nature of the data (Raudenbush and Bryk 2002; Snijders and Bosker 1999). We use linear models here, treating the ancestry question responses as interval level data. ${ }^{[7]}$

4.4 In terms of measuring the contextual independent variables, we use two measures of economic development. The first is a measure of GDP per capita (adjusted for purchasing power parities) in the survey year (2003). The second is a measure of GDP at the time of national foundation, derived from the estimates developed by economist Angus Maddison (Maddison 2001). This allows us to test the hypothesis that the economic development of a society at foundation has lasting effects on the kind of national identity it develops. The national founding date is defined as the first year of independent government, or 1800 for countries that existed earlier than this date. ${ }^{[8]} \mathrm{A}$ scale from 1-3 is employed. Countries with "high" GDP were more affluent than the regional average when they were founded and are coded 3, "medium" GDP refers to countries that were around the regional average for economic development at founding and are coded 2, while "low" GDP refers to countries that were economically backward relative to the regional average at foundation and are coded 1. ${ }^{[9]}$

4.5 In terms of ethnic diversity, we again use two measures at the national level. For changes due to immigration, we use data from the PISA project, an international survey of school children carried out by the OECD ${ }^{[10]}$, which includes questions about the parental national background of 16 year old schoolchildren. We use the proportion of children with a parent born abroad as measure of the size of second generation migrant descended minorities. For the two countries from our sample which were not included in the PISA project ${ }^{[11]}$, we estimate the proportion of second generation migrants directly from the survey, using the proportion of respondents who report having migrant parents. ${ }^{[12]}$ For founding circumstances, a categorical measure based upon historical data was used. Countries which could be considered before 1800 to be established states with stable boundaries form one category (for example France and Britain); countries whose founding circumstances involved some form of largely non-violent secession or unification form a second category (for example New Zealand or Germany); and finally countries based on a violent secession or unification movement make up the third category (for example Ireland or Poland). The first of these, coterminous nation-states at founding, is the reference category with the other two categories included as dummy variables.

4.6 At the individual level, we have categorical measures of education and social class to examine the process of modernization for individual citizens; and a categorical variable for immigrant background. Education is measured using three categories: degree holders, those with secondary school qualifications and those below this level. Class is based on occupation ${ }^{[13]}$ (or spouse's occupation for those with no job), and is divided into six categories: working class; no occupation/unclassifiable; foremen and technicians; the self-employed; lower service class; and upper service class. Immigrant background is measured a simple dummy variable measuring whether respondents have a foreign born parent. A control is also included for gender. We also include a measure of birth cohort in our models to test whether there is any overall pattern of generational change in attitudes in our sample.

4.7 To test the impact of immigration during socialisation on subsequent attitudes we divide our respondents into three categories - those who grew up before migration began, those who grew up during the "first generation" period when immigrants first settled, and those who grew up during the "second generation" period when the native born children of migrants begin to come of age. The first generation period begin when large numbers of migrants first begin to settle in a country, and the second generation period begins 18 years after this point. A country's level of development during socialisation is measured using historical GDP per capita figures compiled by Angus Maddison (Maddison 2001). As the accuracy of such figures will inevitably vary between countries and over time, we reduce them into a series of broad 
categories, with each successive category representing a 50\% increase in GDP per capital over the previous one.

Table 3. Multilevel models predicting ancestry as a condition of national identity: contemporary context and founding conditions

\begin{tabular}{|c|c|c|c|c|}
\hline & $\begin{array}{l}\text { Model } 1 \text { : Individual } \\
\text { conditions only }\end{array}$ & $\begin{array}{l}\text { Model } 2 \text { : socialization } \\
\text { conditions added }\end{array}$ & $\begin{array}{l}\text { Model 3: national } \\
\text { context added }\end{array}$ & $\begin{array}{c}\text { Model 4: historical } \\
\text { context added }\end{array}$ \\
\hline \multicolumn{5}{|l|}{$\begin{array}{l}\text { Social class (ref: working } \\
\text { class) }\end{array}$} \\
\hline Upper service class & $-.17 * *$ & $-.17 * *$ & $-.17^{* *}$ & $-.17^{* *}$ \\
\hline Lower service class & $-.11 * *$ & $-.11 * *$ & $-.11 * *$ & $-.10 * *$ \\
\hline Self-employed & $-.06^{* *}$ & $-.06 * *$ & $-.07 * *$ & $-.07 * *$ \\
\hline Foremen/technicians & -.03 & -.03 & -.03 & -.02 \\
\hline No occupation & $-.05 * *$ & $-.06 * *$ & $-.05 * *$ & $-.05 * *$ \\
\hline \multicolumn{5}{|l|}{ Education (ref: low) } \\
\hline Degree & $-.38 * *$ & $-.38 * *$ & $-.38 * *$ & $-.38 * *$ \\
\hline Medium & $-.16 * *$ & $-.16 * *$ & $-.16 * *$ & $-.16^{* *}$ \\
\hline $\begin{array}{l}\text { Migrant status (ref: } \\
\text { native) }\end{array}$ & & & & \\
\hline $1^{\text {st }}$ or $2^{\text {nd }}$ generation & $-.50 * *$ & $-.55 * *$ & $-.65 * *$ & $-.66^{* *}$ \\
\hline Female & $.01 *$ & $.01^{*}$ & $.01 * *$ & $.01^{* *}$ \\
\hline \multicolumn{5}{|l|}{ Cohort (ref: Pre-1930) } \\
\hline $1930-1945$ & $-0.14 * *$ & $-.10 * *$ & $-.10 * *$ & $-.10 * *$ \\
\hline $1946-1959$ & $-0.36 * *$ & $-.22 * *$ & $-.22 * *$ & $-.22 * *$ \\
\hline $1960-1974$ & $-0.46 * *$ & $-.26 * *$ & $-.26 * *$ & $-.27 * *$ \\
\hline $1975-1988$ & $-0.61^{* *}$ & $-.36 * *$ & $-.36 * *$ & $-.37 * *$ \\
\hline \multicolumn{5}{|l|}{$\begin{array}{l}\text { Socialisation immigration } \\
\text { (ref: pre-migration) }\end{array}$} \\
\hline $1^{\text {st }}$ generation imms & & $-.13 * *$ & $-.13 * *$ & $-.13^{* *}$ \\
\hline $2^{\text {nd }}$ generation imms & & $-.23 * *$ & $-.22 * *$ & $-.22 * *$ \\
\hline \multicolumn{5}{|l|}{$\begin{array}{l}\text { Socialisation GDP per } \\
\text { capita (ref: Under } \$ 3000 \\
1990 \text { ) }\end{array}$} \\
\hline$\$ 3000-\$ 4500$ & & .01 & .01 & .01 \\
\hline$\$ 4500-\$ 7000$ & & -.02 & -.02 & -.02 \\
\hline$\$ 7000-\$ 10500$ & & $-.14^{* *}$ & $-.14 * *$ & $-.13 * *$ \\
\hline$\$ 10500-\$ 16000$ & & $-.27^{* *}$ & $-.27 * *$ & $-.25^{* *}$ \\
\hline$\$ 16000$ plus & & $-.28 * *$ & $-.28 * *$ & $-.26 * *$ \\
\hline Log GDP, standardised & & & $-.16^{* *}$ & $-.13^{* *}$ \\
\hline$\%$ of $2^{\text {nd }}$ gen. Immigrants & & & -.01 & -.003 \\
\hline GDP founding ( $1-3$ scale) & & & & .01 \\
\hline \multicolumn{5}{|l|}{$\begin{array}{l}\text { Founding circumstances } \\
\text { (ref: nation-state) }\end{array}$} \\
\hline Non-violent secession & & & & .07 \\
\hline Violent secession & & & & .00 \\
\hline Intercept & $3.42 * *$ & $3.46 * *$ & $3.48^{* *}$ & $3.41 * *$ \\
\hline $\mathrm{N}$ (Groups) & 32 & 32 & 32 & 32 \\
\hline $\mathrm{N}$ (Individuals) & 41,516 & 41,516 & 41,516 & 41,516 \\
\hline $\mathrm{R}^{2}$ within countries & & & 0.10 & 0.10 \\
\hline$R^{2}$ between countries & & & 0.56 & 0.55 \\
\hline
\end{tabular}

${ }^{*} \mathrm{p}<.05^{* *} \mathrm{p}<01$. Source: Intemational Social Survey Programme, 2003

4.8 Model 1 of Table 3 shows the impact of the individual level factors upon support for the ancestry measure of ethnic nationalism. As expected, members of the service class and the more educated tend to show less support for ethnic nationalism. Those without parents who were citizens are also much less likely to support an ethnic conception of national identity, which is more likely to exclude them from the national in-group. We also find some initial evidence that generational differences may be important: support for the ancestry measure we employ declines in almost linear fashion as we move from older to younger cohorts. 
4.9 While the effects of education and citizenship fit with our expectations, these individual-level factors leave much of the country level variation unexplained. As the $R^{2}$ values show, only seven per cent of the variance between countries is explained by compositional differences. Model 2 adds in the two socialisation variables measuring levels of economic development and ethnic diversity when respondents were growing up. We find robust evidence for socialisation effects. Both GDP levels and immigration conditions during socialisation have a highly significant correlation with national identity beliefs. Those who grow up in more prosperous economic conditions, and in societies where mass migration has already begun, are less likely to support ancestry as a measure of identity. Controlling for socialisation conditions greatly reduces the size of the overall cohort coefficients, particularly for the youngest cohorts, suggesting that the lower support for ethnic national identity among the young may be in large part the result of growing up in more prosperous, economically integrated and ethnically diverse societies. Once socialisation effects are included, the between countries $\mathrm{R}$ squared measure rises to 39 per cent, indicating that a large portion of the differences between nation can be accounted for by differences in the socialisation conditions their citizens experienced.

4.10 Model 3 adds in national level measures of contemporary GDP and immigrant minority size. These variables have a significant impact, with the $\mathrm{R}^{2}$ figure for differences between nations rising to 57 per cent. The effect of current economic development is both statistically significant and substantively large - a one standard deviation increase in log GDP reduces support for the ancestry measure of national identity by as much as middle class membership at the individual level. There is no robust evidence that current ethnic diversity exerts an effect, however. Model 4 adds in historical measures of relative GDP and founding circumstances. We do not find any evidence that either has a robust impact on current national identity beliefs, suggesting that lasting differences between countries do not seem to have resulted from these differences in their early social and economic conditions, at least on these admittedly crude measures.

4.11 While more distant history does not seem to have left a lasting imprint on the nations of our sample, more recent developments have left their mark through the mechanism of socialisation. New generations socialised into economically modernised and ethnically diverse societies progressively abandon the attachment to ancestry as a measure of national identity favoured by their parents and grandparents. The effects are illustrated in Figure 1, which compares the generational distribution of predicted ancestry scores in two idealised nations. Nation 1 fits the profile seen in countries such as the Philippines: it is currently poor, and has experienced low growth in per capita income and has not yet experienced an influx of immigrants. Nation 2 fits the profile seen in countries such as Germany: it is currently rich, but older cohorts grew up in much poorer circumstances, and it experienced a wave of migration which began during the 1960s. Support for the ancestry measure is consistently higher in Nation 1, reflecting its relative poverty, and also shows only a small decline from one generation to the next. In Nation 2, which has a rapidly growing economy and from 1960 a diversifying society, there is a rapid decline in support for the ancestry measure as we move from older to younger cohorts, with a difference of nearly one point on the four point scale between the oldest and youngest cohorts. The oldest generations in the two countries have similar attitudes, but the younger cohorts are very different: younger people in Nation 1 continue to rate ancestry as important while younger citizens in Nation 1 have abandoned it.

Figure 1. The effects of cohort socialisation and national context illustrated

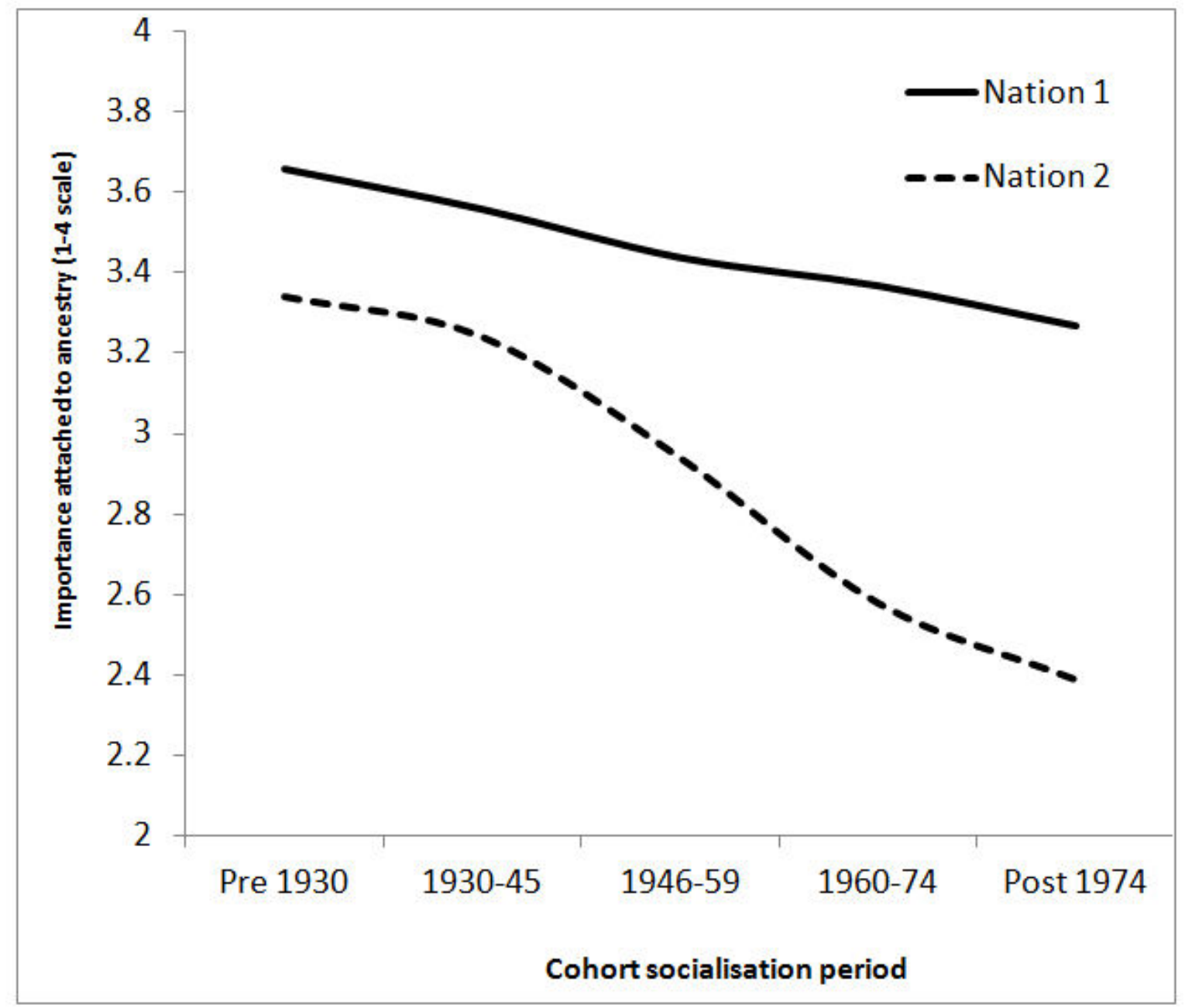


Source: Model 4 of Table 4. These scores refer to a working class man with a medium level of education with parents that are both citizens of his country. Country 1 has current GDP 1 standard deviation below the sample average, and had GDP per capital below $\$ 4,500$ until 1960 , and then below $\$ 7,500$ until the present day. Country 1 has not experienced a major wave of immigration Country 2 has current GDP 1 standard deviation above the sample average, and had GDP per capita below $\$ 4,500$ until 1946, below $\$ 7,000$ until 1953, below $\$ 10,500$ until 1960 , and below $\$ 16,000$ until 1974 . GDP per capita is above $\$ 16,000$, the highest category, thereafter. Mass immigration to country 2 began in 1960, and so those coming of age after 1978 are socialised into the second post migration generation.

4.12 Our individual and national level predictors, principally the economic development variables, explain the majority of the considerable variance in ethnic nationalist attitudes between countries. This is illustrated by Figure 2, which plots the relationship between the actual mean scores of ethnic nationalism for each country against our predicted values from model 3 . Most of the country predictions fall quite close to the 45 degree line, indicating a relatively low overall level of error, although there are some noteable outliers. We might note citizens in Ireland, Japan and the US place greater emphasis on ancestry than our model predicts, while citizens in Slovakia, Sweden and the Netherlands score lower on the ancestry measure than our model would lead us to expect. Nonetheless, the model performs very well in predicting country level differences given the relatively small number of predictors included to explain these.

Figure 2. Actual vs. predicted (from model 2) mean ethnic nationalism scores by country

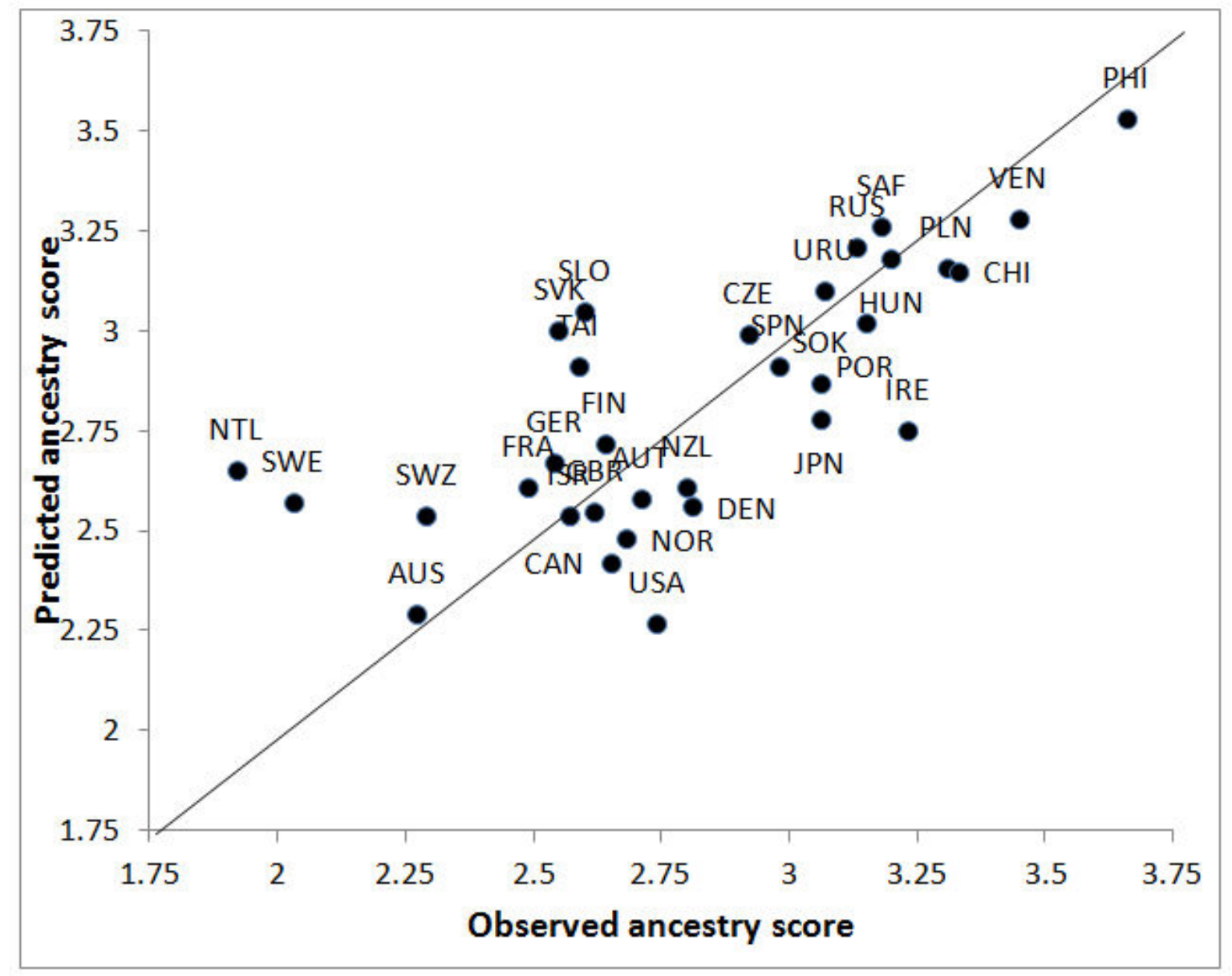

\section{Discussion}

5.1 This paper set out to examine why nations, and individuals within these nations, vary in the emphasis they place on ancestry as a relevant measure of national group membership. We focussed on this measure as it is the strongest and most consistent measure of "ethnic" nationalism for the countries in our sample. We hypothesised that economic development and ethnic diversity would be centrally important predictors of such ethnic nationalism, operating at the individual level, through cohort socialisation, through contemporary national conditions and as a legacy of the historical conditions in countries when nationalist movement first got underway.

5.2 At the individual level, we did indeed find evidence that the more economically secure and highly educated sections of society attach less importance to ancestry as a criterion for national group membership, as do those with immigrant heritage. Put simply, those whose work, family and friendship networks increasingly cross borders effortlessly no longer see the relevance of deep ancestral roots as a measure for deciding belongs to their nation. Similarly, the growing population of citizens whose family history or personal experience involves moving from one nation to settle in another are not willing to support a criterion for national membership which would exclude them.

5.3 We find that these individual differences, though important, cannot account for most of the large variations in ethnic nationalism between our countries. Two other factors seem to account for most of these differences. The first is contemporary prosperity. Those who live in richer countries seem to be consistently less willing to support ancestry as a condition for national group membership. As we use a highly aggregated measure of economic circumstances, GDP per capita, we cannot be sure which aspects of the modernisation process are driving this relationship, but the evidence does suggest a robust 
5.4 The second key factor we have identified is the conditions prevalent when respondents are growing up. We observe large generational differences in the nationalist beliefs of our sample, and these are strongly related to the economic and social conditions prevalent when respondents were growing up. Those who grow up during periods when a country was poorer are consistently more likely to emphasise ancestry as a factor in national identity, but once GDP per capita rises above a certain threshold, ancestry becomes consistently less relevant as conditions during socialisation become more prosperous. Those who grew up in societies which have not experienced any significant wave of migration place greater emphasis on ancestry than those who grow up during the onset of migration, who in turn place greater emphasis on ancestry than those who grow up with the children of migrants.

5.5 Both findings suggest that the recent histories of nations have a lasting effect on the nationalist attachments of their citizens. Older citizens in countries which have developed or diversified rapidly will retain ethnic feelings of nationalism shaped by the poorer, more homogenous societies in which their values and attitudes were formed. As a result, patterns of national attachment in the aggregate will respond very slowly to social change, as new generations with values forged in a different kind of society gradually replace older ones. This raises the possibility of political conflict between generations with very different understandings of what national membership means.

5.6 While we have found recent national history exercises a strong effect on the nationalist affiliations of citizens, we did not find any evidence that more distant historical conditions have any such effect. Neither levels of prosperity in the early period of nationalism, nor the manner in which nations came into being, seem to have any robust correlation with the current views of citizens. While our measures of such historical conditions are of course limited, and it is quite possible that alternative, more nuanced measures would produce different results, we may tentatively conclude that we cannot trace differences in national affiliations among citizens to differences in the formative conditions of their nations. This does not mean that such historical factors have no lasting influence on nationalism; they may for example have a lasting influence on the symbolic, institutional and legal expressions of nationalism. However, it does suggest that contemporary nationalist affiliations among the mass public may be primarily shaped by current circumstances rather than long standing traditions.

Appendix: Replication of table 3 regression models using ordered logistic regression

\begin{tabular}{|c|c|c|c|c|}
\hline & $\begin{array}{l}\text { Model 1: Individua } \\
\text { conditions only }\end{array}$ & $\begin{array}{l}\text { Model 2: socialization } \\
\text { conditions added }\end{array}$ & $\begin{array}{l}\text { Model 3: national } \\
\text { context added }\end{array}$ & $\begin{array}{l}\text { Model } 4 \text { : historical } \\
\text { context added }\end{array}$ \\
\hline \multicolumn{5}{|c|}{$\begin{array}{l}\text { Social class (ref: working } \\
\text { class) }\end{array}$} \\
\hline Upper service class & $-.34 * *$ & $-.31 * *$ & $-.32 * *$ & $-.34 * *$ \\
\hline Lower service class & $-.21 * *$ & $-.19 * *$ & $-.21 * *$ & $-.21 * *$ \\
\hline Self-employed & $-.15 * *$ & $-.11 * *$ & $-.15 * *$ & $-.15 * *$ \\
\hline Foremen/technicians & -.06 & -.03 & -.05 & -.05 \\
\hline No occupation & $-.12 * *$ & $-.09 * *$ & $-.13 * *$ & $-.11 * *$ \\
\hline \multicolumn{5}{|l|}{ Education (ref: low) } \\
\hline Degree & $-.69 * *$ & $-.74 * *$ & $-.73 * *$ & $-0.71 * *$ \\
\hline Medium & $-.31 * *$ & $-.35 * *$ & $-.34 * *$ & $-0.33^{* *}$ \\
\hline \multicolumn{5}{|l|}{ Migrant status (ref: native) } \\
\hline $1^{\text {st }}$ or $2^{\text {nd }}$ generation & $-1.32 * *$ & $-1.27^{* *}$ & $-1.32^{* *}$ & $-1.31 * *$ \\
\hline \multicolumn{5}{|l|}{ Gender:female } \\
\hline \multicolumn{5}{|l|}{ Cohort (ref: Pre-1930) } \\
\hline $1930-1945$ & $-.30 * *$ & $-.20 * *$ & $-.24 * *$ & $-.25 * *$ \\
\hline $1946-1959$ & $-.73 * *$ & $-.38 * *$ & $-.50 * *$ & $-.53 * *$ \\
\hline $1960-1974$ & $-.96 * *$ & $-.45 * *$ & $-.61 * *$ & $-.65 * *$ \\
\hline $1975-1988$ & $-1.24 * *$ & $-.62 * *$ & $-.79 * *$ & $-.86^{* *}$ \\
\hline \multicolumn{5}{|l|}{$\begin{array}{l}\text { Socialisation immigration } \\
\text { (ref: pre-migration) }\end{array}$} \\
\hline $1^{\text {st }}$ generation imms & & $-.23 * *$ & $-.23 * *$ & $-.21 * *$ \\
\hline
\end{tabular}


Log GDP, standardised

$\%$ of $2^{\text {nd }}$ gen. Immigrants

Founding circumstances

(ref: nation-state)

Non-violent secession

Violent secession

\section{Cut point 1 \\ Cut point 2 \\ Cut point 3}

\author{
$\mathrm{N}$ (Groups) \\ $\mathrm{N}$ (Individuals)
}

-2 Log likelihood

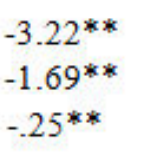

41,516

41,516

$-51774$

\section{$-3.23 * *$ \\ $-1.68 * *$ \\ $-.23 * *$ \\ 32 \\ 41,516 \\ $-51654$}

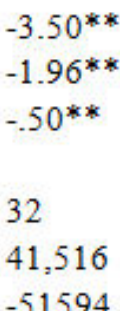

$-3.42 * *$

$-1.89 * *$ $-.46 * *$

32

41,516

$-51600$

\section{Notes}

${ }^{1}$ We should note that the terminology used to describe this type of nationalism is more contested than that associated with civic nationalism. Nieguth (1999) argues for a more complex typology particularly with regard to what ethnic and cultural nationalism mean, and Shulman (2002) separates the civic, cultural and ethnic components of national identity in his study comparing the nationalisms of East and West. Nonetheless as we concentrate on the clearest 'ethnic' element of nationalism, ancestry, we would argue that the division between cultural, ethnic and civic nationalism issue is less relevant to our study.

2 Similarly high numbers of people thought that the other possible civic items were important: 89 per cent saying that 'feeling' part of their nationality was fairly or very important, and also 89 per cent saying that speaking the national language was fairly or very important.

${ }^{3}$ There are some opposing arguments to this consensus. Smith (1995) takes almost the opposite view, arguing that the ability to develop and maintain networks of communication over vast distances may help to develop and maintain ethnic and cultural identities, and foster the development of smaller, newer ethnic loyalties (Smith 1995, p 25-8).

${ }^{4}$ Although we recognise this is not completely clear cut as immigration may potentially also encourage greater emphasis on ethnically-based conceptions of nationalism amongst the majority group population, perhaps particularly if migrant minorities are regarded as a threatening source of economic competition or social and cultural problems (Triandafyllidou, 1998; Kunovich, 2006).

${ }^{5}$ In fact 34 in total, but Bulgaria and Latvia are missing the dependent variable in our analyses.

6 It could be argued that a random effects model is inappropriate in this case, since our 32 countries cannot be regarded as a sample of a population. We would argue that since we want to come to general conclusions about the effect of contextual variables, our selection of countries can be seen as a sample of a larger hypothetical population of countries, and our modelling choice is therefore justifiable.

7 Strictly speaking it is of course ordinal, but we use linear models here to give easily interpretable coefficients and aid explanation. The non-linear function used in an ordinal regression means that the predicted effects of individual independent variables depend on the values assigned to other variables. This makes interpretation of findings more complex and in particular makes graphical display of predicted effects more difficult. We therefore present findings from a linear regression model in the main text. Replication of all models here with ordinal logit hierarchical models gives essentially the same results, with the substantive significance of the main findings unchanged. A full table of ordered logistic regression results, calculated using the GLAMM programme in STATA, is included in the Appendix.

81800 was chosen as there is a consensus that nations and nationalism rose to prominence in the 19th century, even if they had in some cases existed before this point. Before this date it is also difficult to gather reliable comparative economic statistics. 
9 These categorisations were made using GDP per capita estimates from Maddison (2001). Clearly they are to some extent a matter of judgement, although our results appear fairly robust to changes in the classification of individual countries. Full details of country codings are available from the authors on request.

10 Further details of the PISA project are available at www.pisa.oecd.org.

11 Venezuela and the Philippines

12 We have also replicated the analysis with these two cases excluded. This has no effect on our results.

13 Spouse's occupation is used for those without a job. Unfortunately this measure of class is not completely comparable across countries, as in some surveys respondent's previous occupation was coded for the retired and unemployed whereas in other it was not. This means that the "no occupation or unclassifiable" category does differ in meaning somewhat from country to country.

\section{References}

ANDERSON, B (1983) Imagined Communities: Reflections on the origins and spread of nationalism, London: Verso.

BJORKLAND, F (2006) "The Eastern European "ethnic nation": myth or reality?", European Journal of Political Research 45(1): 93-121 [doi:://dx.doi.org/10.1111/j.1475-6765.2005.00292.x]

BREUILLY, (1993)

BRUBAKER, R (1992) Citizenship and Nationhood in France and Germany, Cambridge, MA: Harvard University Press

BRUBAKER, R (1996) Nationalism Reframed: Nationhood and the National Question in the New Europe, Cambridge: Cambridge University Press

BRUBAKER, R (2004) Ethnicity Without Groups, Cambridge: Harvard University Press

BRUBAKER, R and Laitin, D (1998) "Ethnic and Nationalist Violence", Annual Review of Sociology 24: 423-52 [doi:://dx.doi.org/10.1146/annurev.soc.24.1.423]

COLLEY, L (1996) Britons: Forging the Nation 1707-1837, London: Vintage.

CONNOR, W (1994) Ethnonationalism: The Quest for Understanding, Princeton: Princeton University Press

DAY, G and Thompson, A (2004) Theorizing Nationalism Basingstoke: Palgrave Macmillan.

DOGAN, M (1994) 'The decline of nationalisms in Western Europe', Comparative Politics 26 (3), 281-305. [doi:://dx.doi.org/10.2307/422113]

FORD, R (2008) "Is racial prejudice declining in Britain?", British Journal of Sociology 59(4): 609-36 [doi:://dx.doi.org/10.1111/j.1468-4446.2008.00212.x]

GELLNER, E (1964) 'Nationalism' in Thought and Change, London: Weidenfield \& Nicholson.

GELLNER, E (1983) Nations and Nationalism, Oxford: Blackwell.

GIDDENS, A (1987) The Nation-State and Violence, Berkley, CA: University of California Press

GUIBERNAU, M (1996) Nationalisms: The nation state and nationalism in the twentieth century, Cambridge: Polity Press.

HEARN, J (2006) Rethinking Nationalism: A Critical Introduction, Basingstoke: Palgrave Macmillan

HEATH, A and Tilley, J (2005) 'British National Identity and Attitudes Towards Immigration", International Journal on Multicultural Societies 7(2):119-33

HJERM, M (1998) 'National identities, national pride and xenophobia: A comparison of four Western countries', Acta Sociologica 41 (4) 335-347.

HJERM, M (2003) 'National sentiments in Eastern and Western Europe', Nationalities Papers 31 (4) 413429. [doi:://dx.doi.org/10.1080/0090599032000152933]

HOBSBAWM, E (1990) Nations and nationalism since 1780, Cambridge: Cambridge University Press.

HOLTON, R (1998) Globalization and the Nation State, Basingstoke: Palgrave.

INGLEHART, R (1997) Modernisation and Postmodernisation: Cultural, economic and political change in 43 societies, Princeton: Princeton University Press.

IVARSFLATEN, E (2005) "Threatened by Diversity: Why Restrictive Asylum and Immigration Policies Appeal to Western Europeans", Journal of Elections, Public Opinion and Parties 15(1): 21-45 [doi:://dx.doi.org/10.1080/13689880500064577]

JONES, F and Smith, P (2001a) 'Diversity and commonality in national identities: An exploratory analysis of cross-national patterns', Journal of Sociology 37(1): 45-63.

[doi:://dx.doi.org/10.1177/144078301128756193] 
JONES, F and Smith, P (2001b) 'Individual and societal bases of national identity: A comparative multilevel analysis', European Sociological Review 17(2): 103-118. [doi:://dx.doi.org/10.1093/esr/17.2.103]

KOHN, H (1944) The Idea of Nationalism, New York: Macmillan.

KUNOVICH, R (2006) "An Exploration of the Salience of Christianity for National Identity in Europe", Sociological Perspectives 49:435-60 [doi:://dx.doi.org/10.1525/sop.2006.49.4.435]

KUNOVICH, R (2009) "The Causes and Consequences of National Identification", American Sociological Review 74:573-593 [doi:://dx.doi.org/10.1177/000312240907400404]

MADDISON, A (2001) The World Economy: Historical Statistics, Paris: Development Centre of the Organisation for Economic Co-Operation and Development.

MANN, M (1996) "Nation-states in Europe and Other Continents: Diversifying, Developing, not Dying", in Balakrishnan, G (ed) Mapping the Nation, London: Verso.

MANNHEIM, K (1952) "The problem of generations", in Essays on the Sociology of Knowledge, Oxford: Oxford University Press

MCCRONE, D (1998) The Sociology of Nationalism, London: Routledge.

MCCRONE, D and Surridge, P (1998) 'National Identity and National Pride' in Jowell, R; Curtice, J; Park, A; Brook, L; Thomson, K and Bryson, C (eds) British and European Social Attitudes: The $15^{\text {th }}$ report, Aldershot: Ashgate.

MCLAREN, L (2003)

MEINECKE (1907) Cosmopolitanism and the Nation State, Princeton, NJ: Princeton University Press.

MILLER, D (1995) On Nationality, Oxford: Clarendon Press.

MILLER, D (2000) Citizenship and National Identity, Cambridge: Cambridge University Press

MUDDE, C (2007) Populist Radical Right Parties in Europe, Cambridge: Cambridge University Press

NIEGUTH, T (1999) 'Beyond dichotomy: Concepts of the nation and the distribution of membership', Nations and Nationalism 5:155-173. [doi:://dx.doi.org/10.1111/j.1354-5078.1999.00155.x]

RAUDENBUSH, S and Bryk, A (2002) Hierarchical Linear Models: applications and data analysis methods, Thousand Oaks: Sage Publications ( $2^{\text {nd }}$ edition).

REESKENS, T and Hooghe, M (2010) "Beyond the civic/ethnic dichotomy: investigating the structure of citizenship concepts across thirty-three countries", Nations and Nationalism 16(4): 579-97.

SHULMAN, S (2002) 'Challenging the civic/ethnic and West/East dichotomies in the study of nationalism', Comparative Political Studies 35 (5): 554-585. [doi:://dx.doi.org/10.1177/0010414002035005003]

SMITH, A (1991) National Identity, Harmondsworth: Penguin.

SMITH, A (1995) Nations and Nationalism in a Global Era, Cambridge: Polity Press.

SMITH, A (1998) Nationalism and Modernism, London: Routledge.

SNIJDERS, T and Bosker, R (1999) Multilevel Analysis: An introduction to basic and advanced multilevel modelling, London: Sage.

TILLEY, J (2002) "Political Generations and Partisanship in the UK", Journal of the Royal Statistical Society A: Statistics in Society 165(1): 121-35

TILLEY, J (2005) "Libertarian-Authoritarian Value Change in Britain 1974-2001", Political Studies 53: $442-53$ [doi:://dx.doi.org/10.1111/j.1467-9248.2005.00537.x]

TILLEY, J; Heath, A and Exley, S (2004) 'Dimensions of British identity' in Park, A; Curtice, J; Thomson, K; Bromley, C and Phillips, M (eds) British Social Attitudes: The $19^{\text {th }}$ Report London: Sage.

TILLY, C (1975) 'Reflections on the History of European State-Making', in Tilly, C(ed.) The Formation of National States in Western Europe, Princeton, NJ: Princeton University Press

TRIANDAFYLLIDOU, A (1998) "National Identity and the 'Other"', Ethnic and Racial Studies 21:593-612

WEBER, E (1976) Peasants into Frenchmen: The Modernization of Rural France 1870-1914, Stanford, CA: Stanford University Press 